\title{
ACCOMMODATION OF L2 SPEECH IN A REPETITION TASK: EXPLORING PARALINGUISTIC IMITATION
}

\author{
LÉA BURIN \\ Paris Diderot University, France \\ lea.burin@univ-paris-diderot.fr
}

\begin{abstract}
Phonetic convergence is the process by which a speaker adapts his/her speech to sound more similar to his/her interlocutor. While most studies analysing this process have been conducted amongst speakers sharing the same language or variety, this experiment focuses on imitation between non-native and native speakers in a repetition task. The data is a fragment from the ANGLISH corpus designed by Anne Tortel (Tortel, 2008). 40 French speakers (10 male intermediate, 10 male advanced, 10 female intermediate and 10 female advanced learners) were asked to repeat a set of 20 sentences produced by British native speakers. Segmental (vowel quality), suprasegmental (vowel duration) and voice quality were analysed. Level of proficiency, gender and model talker were taken as independent variables.

Level appeared not to be a relevant parameter due to a high amount of inter-individual variability amongst groups. Somewhat contradictory results were observed for vowel duration and F1-F2 distance for male learners converged more than female learners. Our hypothesis that low vowels display a higher degree of imitation, and especially within the F1 dimension (Babel, 2012), was partially validated. Convergence in vowel duration in order to sound more native-like was also observed (Zając, 2013).

Regarding the analysis of voice quality, and more particularly of creaky voice, observations suggest that some advanced female learners creaked more than the native speakers and more in the reading task, which indicate, both linguistic idiosyncrasy and accommodation towards the native speakers. Low vowels seem also to be more likely to be produced with a creaky voice, especially at the end of prosodic constituents.
\end{abstract}

Keywords: imitation, convergence, vowel spectra, vowel duration, creaky voice

\section{Introduction}

\subsection{Phonetic accommodation}

Phonetic accommodation emerged from Communication Accommodation Theory (CAT) developed by Giles et al. in the early seventies. This theory argues that when people are involved in a conversation, they accommodate to others at different levels. One can mimic the postures, the mannerisms, or the facial expressions of interaction partners (Chartrand and Bargh, 1999: 893). Although people can imitate the persons they are interacting with spontaneously, it is mostly an unconscious process than can be strategic, and is motivated (Coupland and 
Giles, 1988: 175) in order to, for instance, "improve communication at the social level and/or at the intelligibility level" (Garnier et al., 2013: 1).

The process of accommodation can be subdivided into three distinct subcategories: divergence, maintenance and convergence.

1. One can diverge from one conversational partner in order to lower social approval (Giles et al., 1991:32), and as a way of increasing social distance (Babel, 2012: 179). In this case, speakers will accentuate speech differences between themselves and their interlocutors.

2. One can maintain his/her natural way of speaking in order to maintain one's group identity (Bourhis, 1979).

3. One can adjust one's speech to sound more similar to his/her interlocutor (Babel, 2012: 177), leading to a decrease in the dissimilarities of acousticphonetic forms between talkers. This phenomenon has been the most frequently observed amongst conducted studies and is known as 'phonetic convergence'.

Speech rate and fundamental frequency have been proved to be the two features most prone to be imitated (Pardo, 2010; Sato et al., 2013). Many other prosodic features such as utterance length, pausal phenomena (Bilous and Krauss, 1998), vocal intensity (Black, 1949; Natale, 1975) or vowel duration (Zając, 2013) also appear to be subject to accommodation. The main communicative function that emerges from this concept of convergence is to lessen social distance, though accommodation can take place in all types of social situations. It can occur when speakers simply produce words (Goldinger, 1997, 1998; Goldinger and Azuma, 2004; Namy, Nygaard and Sauerteig, 2002), but is mostly observable in socially rich, dyadic conversations (Natale, 1975; Pardo, 2006; Pardo et al., 2010, Babel, 2011).

Welkowitz et al. (1972) showed that pair talkers who perceived themselves as being similar converged more towards each other in terms of vocal intensity than randomly-paired talkers. Giles (1973) analysed a conversation between an inspector and a traveller in a train and observed that the latter would converge towards the speech of the former. Consequently, the way people speak can lead to determine which person is socially dominant in a conversation (Nilsenová and Swerts, 2012: 77). It has been found that, in dyadic conversations, each person is assigned a role and people are more likely to converge towards the person who has more 'power' (Watzlawick et al. 1967).

Gender has also been found to play a role in the process of accommodation. Women appear to converge more than men (Eisikovits, 1987; Namy et al., 2002; Babel, 2012; Babel et al., 2014). A possible explanation for this pattern is that "women might be more sensitive to indexical features ${ }^{1}$ of talkers, which could lead to greater convergence" (Pardo, 2006: 2388). In addition, speakers, whether male

Indexical features are data about a person such as physical, social, and psychological characteristics, e.g. age, gender, social status, and emotional state (Abercrombie, 1967; Laver, 1989; Laver and Trudgill, 1979). 
or female, have a tendency to converge more towards male interlocutors (Bilous and Krauss, 1988; Gallois and Callan, 1988; Willemyns et al. 1997).

Accommodation, and mostly convergence, may also be affected by the talker's perceived attractiveness. People tend to converge towards an interlocutor they appreciate and by whom they want to be appreciated (Giles et al., 1991, Byrne, 1997; Chartrand and Bargh, 1999; Babel, 2009; Babel, 2012). Imitating others has, thus, a clear social function in that it reflects the degree of affiliation we feel and want to elicit in other people (Lakin et al. 2003).

In the literature on second language acquisition (SLA), Giles and Johnson (1987) have found evidence that a non-native speaker will be likely to imitate a native speaker if they both share significant social identities, related to ethnicity or not. However, Zuengler (1982) demonstrated that the L2 pronunciation can vary, by diverging or converging, if a native-English-speaking interlocutor conveys negative or positive attitude towards the ethnic group the non-native speaker belongs to. In the investigation he conducted, non-native speakers who perceived threat would phonetically diverge if they firmly identified as ethnic group members, or if they wanted to defend their ethnic solidarity. Zając (2013) conducted an experiment to determine how phonetic imitation can, or cannot, be influenced by the model talker being a native or a non-native speaker of English. She found that informants converged towards the native model talker and diverged from the non-native model talker. As an explanation, Zając suggested that subjects might have been aware of the foreign accent of the nonnative speaker and have diverged from her in order to distance themselves from other foreign-accented talkers, and converged towards the native model in order to sound more nativelike. This provides strong evidence that non-native speakers use identical strategies to native speakers in order to lower social distance.

\subsection{The current experiment}

This study investigates deliberate phonetic accommodation between native and non-native speakers. The data is a fragment from the ANGLISH corpus designed by Anne Tortel (Tortel, 2008). 40 French learners of English (10 male intermediate, 10 male advanced, 10 female intermediate and 10 female advanced learners) were asked to repeat and imitate a set of 20 sentences produced by two British native speakers (one male and one female). Convergence with the realisations of read speech recorded before the repetition task are analysed.

Previous findings on accommodation in spontaneous speech indicate that female informants tend to converge more than male informants (Namy et al., 2002; Babel, 2009; Babel et al., 2014), and advanced learners to converge more than intermediate learners for "greater L2 usage and proficiency are associated [...] with increased L2 production experience" (Best and Tyler, 2007: 20). We expect female speakers to converge more, whatever their level. On the contrary we expect level to play a role in the type of accommodation observed. Convergence in vowel duration in order to sound more native-like (Zając, 2013) 
and accommodation for low vowels, especially within the F1 dimension (Babel, 2009, 2012), are more likely to be observed. Euclidean distance for normalized F1-F2 will be compared for level of proficiency and gender.

Our last section will discuss specific features traditionally ignored or rejected outside the perimeter of phonetic features and called 'paralinguistic' features, such as creaky voice. Indeed, this sociolinguistic feature consistently appears for some French advanced female learners. Preliminary observations indicate that some advanced female learners creak more than the native speakers, and more in the reading task, which could indicate both linguistic idiosyncrasy and accommodation towards the native speakers. Low vowels also seem to be more likely to be produced with a creaky voice, especially at the end of prosodic constituents.

\section{Methodology}

\subsection{Corpus}

The data used for this research study was collected from the ANGLISH corpus (Tortel, 2008). 20 French intermediate (10 female, 10 male) and 20 advanced learners (10 female, 10 male) of English ${ }^{2}$ were asked to perform two different tasks: first the reading of 4 passages, each related semantically, then the repetition of these same sentences after a native model (Tortel, 2013: 234).

For the sake of naturalness, the repetition task was only carried out once. This has an unfortunate consequence, as the influence of gender cannot be compared for each subject. To make up for this, two model voices have been used for the native realisations: one British female speaker and one British male speaker. The distribution of the corpus between the male and the female voice is, however, slightly unbalanced. The first passage was read by a female native British speaker and the three others were read by the same male native British speaker.

The data used comprised the reading and repetitions of these extracts, along with the production of the two native model talkers, resulting in 815 recordings lasting in average 4 seconds. Subjects could read the text corresponding to the soundfile that was played during the repetition task.

All recordings were made in an anechoic chamber at a frequency of $44 \mathrm{KHz}$ and 16-bit resolution at the Parole et Langage laboratory in Aix-en-Provence, and were done using a headset microphone.

2 Advanced learners were students majoring in English at university, and intermediate learners were adult speakers who did not specialise in English. 


\subsection{Extraction of the acoustic components}

Formant values and vowel duration of all monophthongs occurring in the corpus were extracted, resulting in the analysis of 12,610 phonemes.

Front vowels /I, i, i:, e, æ/, back vowels /u:, $v, \Lambda, \mathrm{o}$ :, p, a:/ and the central vowel /3:/ were analysed. Vowels are coded through the whole study according to Wells' Lexical Set (Wells, 1982).

F1 and F2 values were extracted using a Praat script for each target vowel at different percentages of the distance from the onset to the offset (respectively $25 \%, 50 \%$ and $75 \%$ ) of the vowels. The average value was then calculated to obtain a single, mean value for each vowel.

Duration was extracted for each target vowel and for each speaker with a Praat script designed by Mietta Lennes. ${ }^{3}$

\subsection{Analysing the acoustic components}

The point of this research study is to determine how the participants' production changed after auditory exposure to the model talkers. The method used is the same as the one used by Babel (2012) which consists in calculating the distance value of how the production of a particular vowel evolves through the course of the experiment. This distance value is referred to as the 'difference in distance'. ${ }^{4}$

The difference in distance was first compared between level, then between gender, and finally between gender and level at the same time. The variable model talker was kept into account, as the difference in distance may not display the same results depending on which model talker learners were repeating.

All vowels were normalized using the Lobanov method.

\section{Results}

\subsection{Difference in distance}

The majority of subjects fall on the negative side of the scale (see Figure 1), indicating a general tendency to converge towards the vowel spectra of the model talkers. Results from a series of $t$-tests showed that the overall difference in distance values between participants were, however, not significant $[\mathrm{M}=-0.0264$, $\mathrm{t}=-1.422, p=0.078]$. It appeared to be also the case for the majority of the vowels. Only three vowels out of twelve displayed significant difference in distance values: the DRESS $[\mathrm{M}=-0.155, p<0.001]$, START $[\mathrm{M}=-0.247, p<0.01]$ and FORCE $[\mathrm{M}=-0.132, p<0.01]$ vowels. These observations demonstrate that there were no effects of imitation across the entire dataset and for each vowel. The

SpeCT - The Speech Corpus Toolkit for Praat - http://www.helsinki.fi/ lennes/praat-scripts/

4 See Babel (2012) for a detailed explanation of how the difference in distance value is calculated. 
following analyses explore whether the observed pattern appeared to be the same across groups.

Average difference in distance for all participants

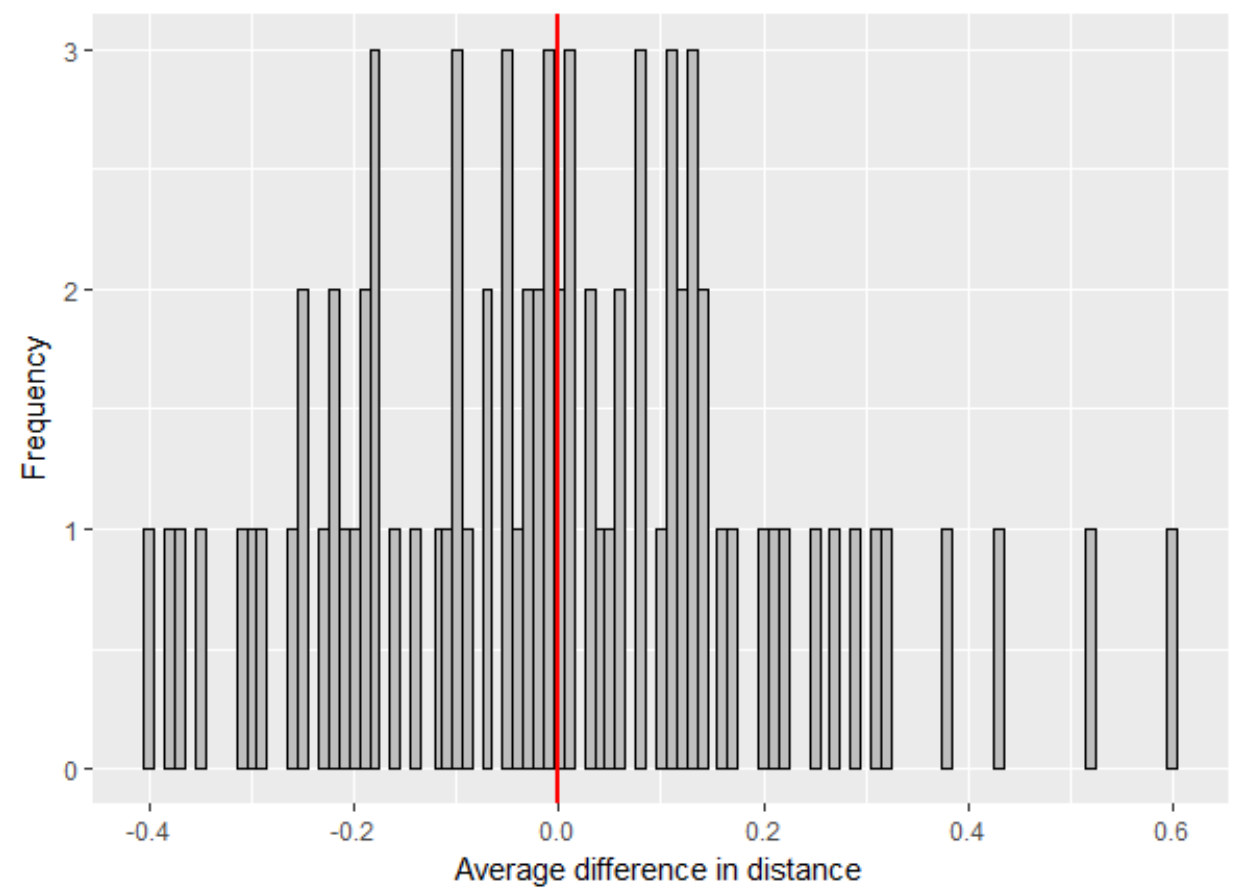

Figure 1. Histogram of all participants' averaged difference in distance value. The red vertical line indicates the 0 point of no change; a positive value indicates vocalic divergence, while a negative value indicates vocalic convergence. The number of subjects is represented on the vertical axis

\subsubsection{Across level}

The majority of advanced learners fall on the negative side on the scale (see Figure 2), indicating a tendency to converge towards both model talkers. In addition, half of the intermediate learners fall on the negative side of the scale and the other half on the positive side. Half of the intermediate learners have therefore diverged from the model talkers, while half have converged towards them. The difference in distance values across level were, however, not significant $[\mathrm{M}(\mathrm{Adv})=-0.024$, $\mathrm{M}(\mathrm{Int})=-0.029, p=0.55]$. The hypothesis that advanced learners accommodate more than intermediate learners cannot be validated. 

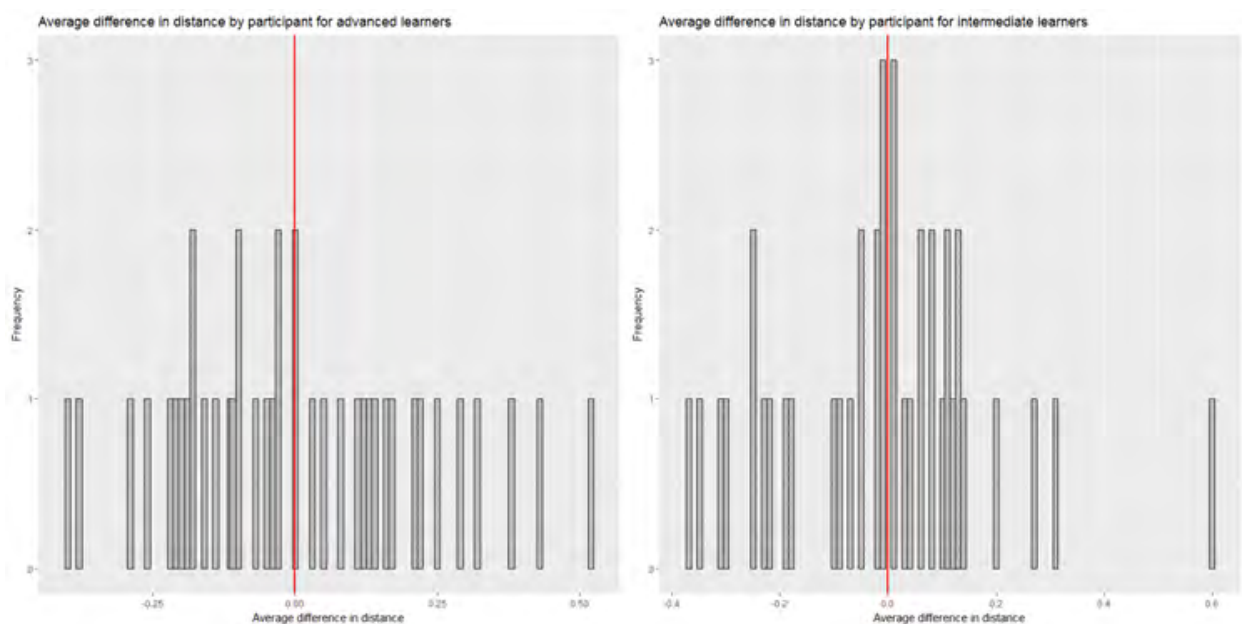

Figure 2. Histograms of each advanced and intermediate learner's averaged difference in distance value. Advanced learners are on the left panel and intermediate learners are on the right panel. The red vertical line indicates the 0 point of no change; a positive value indicates vocalic divergence, while a negative value indicates vocalic convergence

\subsubsection{Across gender}
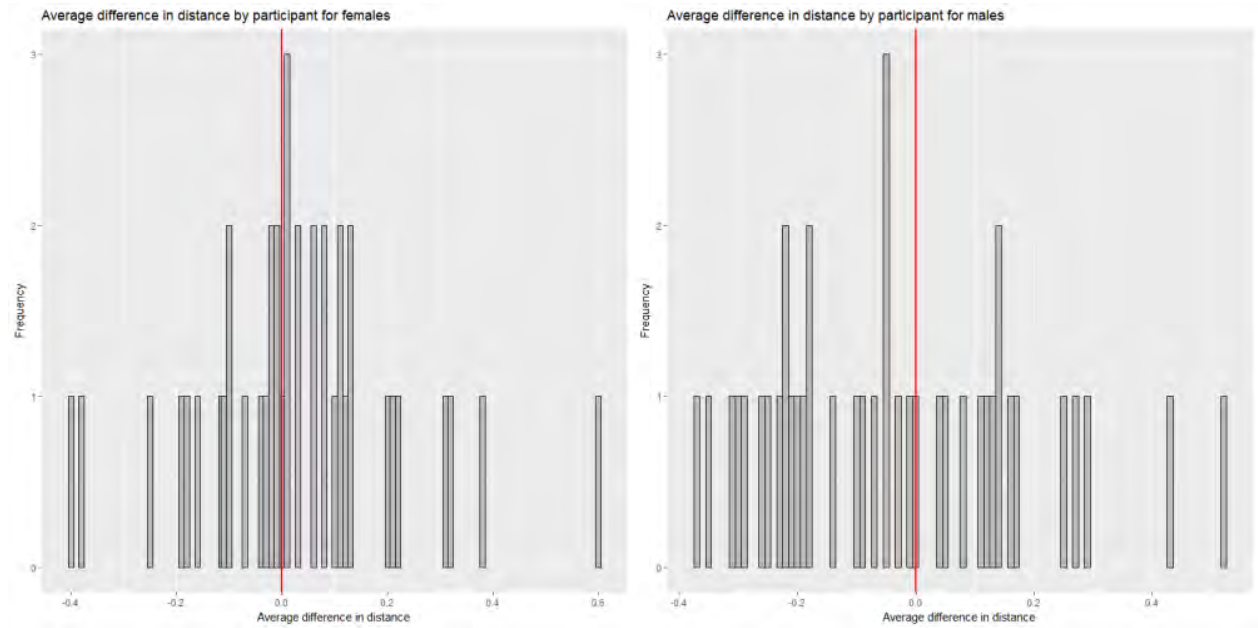

Figure 3. Histograms of each male and female learner's averaged difference in distance value. Female learners are on the left panel, and male learners are on the right panel. The red vertical line indicates the 0 point of no change; a positive value indicates vocalic divergence, while a negative value indicates vocalic convergence

The majority of female participants fall on the positive side of the scale (see Figure 3 ), indicating divergence from the model talkers. Conversely, the majority of male participants fall on the negative side of the scale, indicating a tendency to converge 
towards the vowel spectra of the model talkers. Statistical analyses demonstrated, however, that the difference in distance values across gender was not significant $[\mathrm{M}($ Female $)=-0.008, \mathrm{M}($ Male $)=-0.045, p=0.84]$. The hypothesis that female speakers tend to accommodate more than male speakers cannot be validated.

\subsubsection{A cross-analysis between level, gender and model talker}

The following analyses explore the differences in imitation and the different patterns across groups that arose through the experiment. The results of an ANOVA on the full design are first reported. Subsequently, this is broken down into cases when participants were repeating the male or the female model talker.

The full design of the experiment was a 2 (Model: Female or Male) $\times 2$ (Gender: male or female) $\times 2$ (Level: advanced or intermediate) $\times 12$ (Vowel: KIT, DRESS, TRAP, LOT, STRUT, FOOT, FLEECE, GOOSE, NURSE, START, FORCE, HAPPY) factorial design. There were main effects of Vowel [F $=4.004, p<0.001]$. The two-way Vowel $\times$ Model $[\mathrm{F}=10.641, p<0.01]$ and Vowel $\times$ Gender $[\mathrm{F}=4.333, p<0.001]$ interactions appeared to be significant as well, such as the three-way Vowel $\times$ Gender $\times$ Level $[\mathrm{F}=1.917, p<0.05]$ and Vowel $\times$ Gender $\times$ Model $[\mathrm{F}=4.343, p<0.001]$ interactions. The four-way Vowel $\times$ Gender $\times$ Level $\times$ Model interaction was proved to be insignificant $[\mathrm{F}=0.893$, $p=0.53]$. A post-hoc $t$-test comparing the difference in distance values between male $[\mathrm{M}=-0.064]$ and female model talker $[\mathrm{M}=0.019]$ revealed significantly more imitation in the task of repeating the male model talker [ $\mathrm{t}=-2.197, p<0.05]$, which corroborates previous findings (Bilous and Krauss, 1988; Gallois and Callan, 1988; Willemyns et al. 1997).

The following analyses investigate the two three-way interactions that appeared to be significant (see Figure 4 and Table 1).

Depending on the type of interactions, either $\mathrm{H} 1$ or $\mathrm{H} 2$ is validated but not both at the same time. Moreover, if we compare the number of vowels imitated between advanced and intermediate learners, it appears that advanced learners imitated more vowels than intermediate learners, which correlates with Best \& Tyler's (2007:20) observation that "greater L2 usage and proficiency are associated [...] with increased production experience". Another interesting observation is that the learners' tokens for FLEECE do not display imitation in the majority of cases. This might be due to the fact that KIT and FLEECE are assimilated to one L1 sound, a French-like [i] $]^{5}$. As predicted by the Perceptual Assimilation Model PAM (Best, 1995), discrimination is thus very poor. Production and the ability to accommodate are found to be affected.

5 The tense allophonic realisations for happY are not discussed here. 


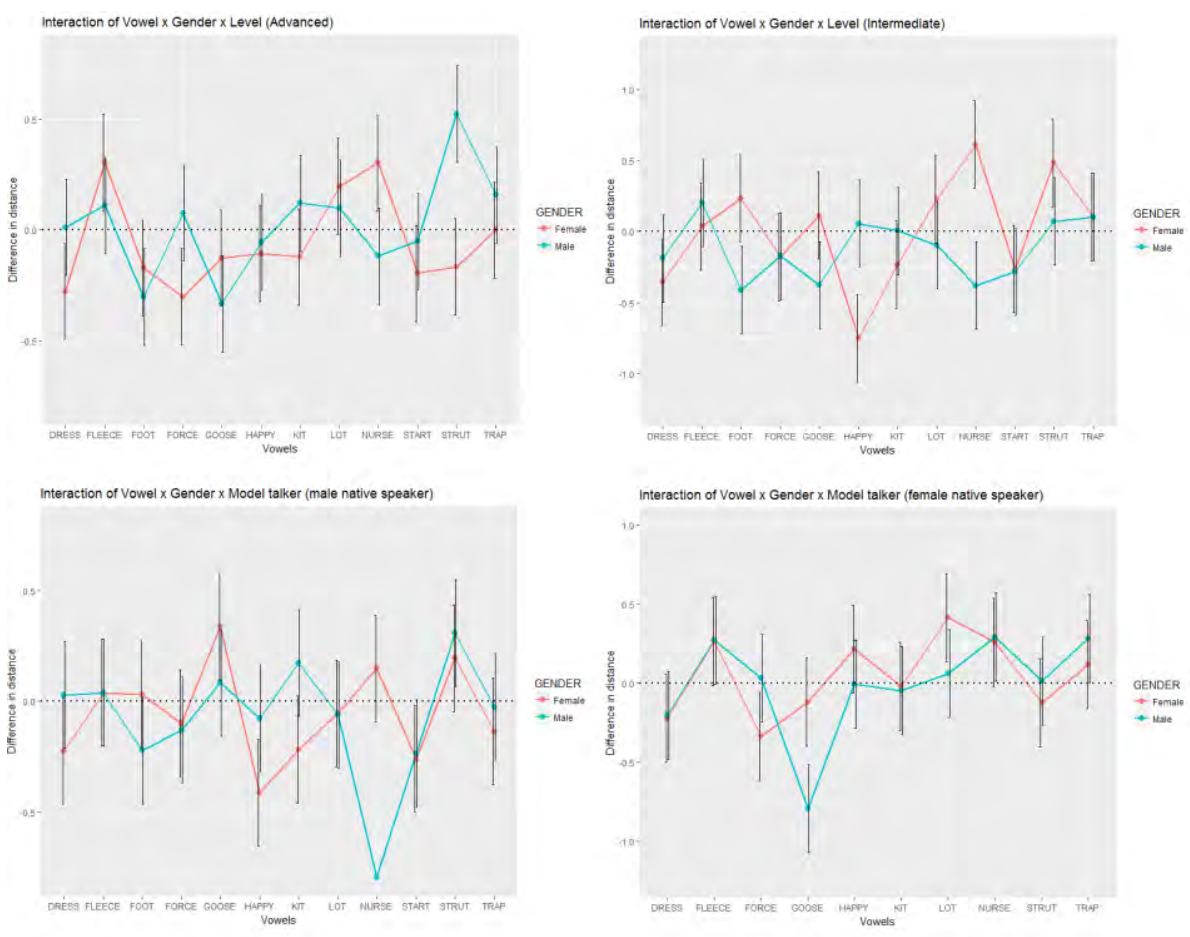

Figure 4. Graphs representing the four types of interaction. The Vowel x Gender $x$ Level (Advanced) interaction is displayed on the top left panel; the Vowel x Gender $\mathrm{x}$ Level (Intermediate) interaction is displayed on the top right panel; the Vowel x Gender x Model (Male native speaker) is displayed on the bottom left panel, and the Vowel x Gender x Model (Female native speaker) is displayed on the bottom right panel. The difference in distance measure on the $y$-axis indicates the amount of phonetic imitation. A value of zero shows no change in vowel production as a result of auditory exposure to the model talker; a positive value indicates vocalic divergence, and a negative value demonstrates vocalic convergence. Error bars are calculated based on the standard deviation of the difference in distance measurements.

Table 1. Summary of the results of the cross-analyses. 1 and 2 indicate that the male learners were more likely to imitate the NURSE vowel than the female learners (posthoc Tukey HSD $=(p<$ 0.05)). 3 indicates that the male learners were more likely to imitate the GOOSE vowel than the female learners (posthoc Tukey HSD $=(p<0.01))$

\begin{tabular}{|l|c|c|}
\hline Interaction Hypothesis & $\begin{array}{l}\text { H1 (female converge more } \\
\text { than male) }\end{array}$ & $\begin{array}{l}\text { H2 (low vowels more } \\
\text { imitated than high vowels) }\end{array}$ \\
\hline $\begin{array}{l}\text { Vowel, Gender, Level } \\
\text { (advanced) }\end{array}$ & $\checkmark$ & $X$ \\
\hline $\begin{array}{l}\text { Vowel, Gender, Level } \\
\text { (intermediate) }\end{array}$ & $X^{1}$ & $\checkmark$ \\
\hline Vowel, Gender, Model (male) & $X^{2}$ & $\checkmark$ \\
\hline Vowel, Gender, Model (female) & $\checkmark^{3}$ & $X$ \\
\hline
\end{tabular}




\subsection{Normalization}

Analyses so far depict the general nature of vowel imitation based on the difference in distance measurements. Normalized formant plots were created to observe the direction of imitation. The three-way interaction vowel by gender by level was found to be insignificant, implying that level is not a meaningful factor. Therefore, it was excluded from the following analyses. This analysis allows for the comparison of the average realisation of learners (in the repetition and reading tasks) compared to that of the models (see Figure 5). It should be borne in my mind that the average represented for each learner actually corresponds to a greater variability (20 female and 20 male learners).
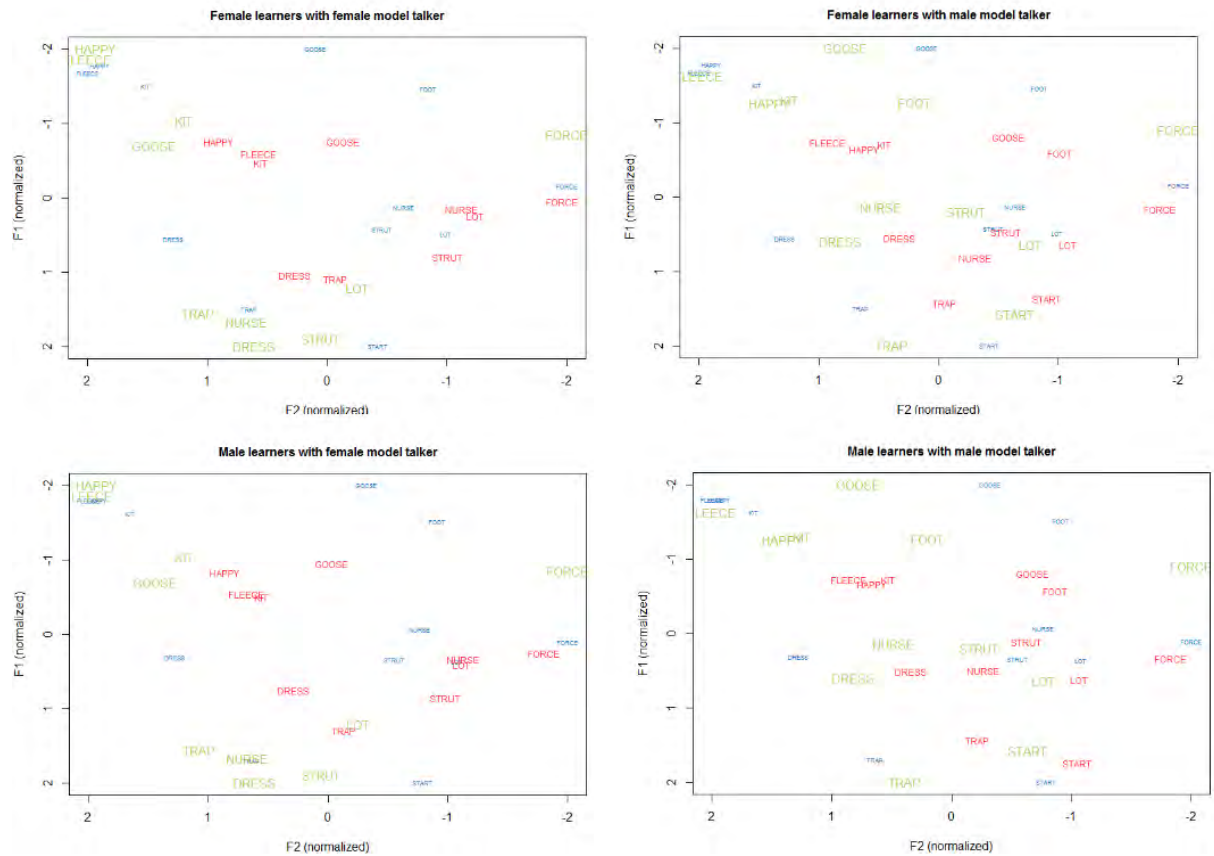

Figure 5. Formant plots displaying the direction of spontaneous phonetic imitation across gender. Female speakers are on the top panels and male learners on the bottom panels. The average baseline of the model talkers' productions is displayed in the green font. The average baseline of participants' productions in the read task is plotted in the blue font and their production in the repetition task is plotted in the red font.

The main observation emerging from the analysis of normalized formant plots is that, in all cases, the production of the FLEECE and HAPPY vowels is more similar to that of natives (green) in the reading task (blue) than in the repetition task (red). In the latter, the three realisations for HAPPY, KIT and FLEECE cluster, suggesting that the distinction is not perceived. From a psycholinguistic 
point of view, general findings show that L2 learners tend to have difficulty differentiating two L2 sounds that do not contrast in the L1, especially when they are phonetically similar to an L1 sound. Several models have been proposed to explain this difficulty in perceiving L2 sounds, such as the Perceptual Assimilation Model - PAM (Best, 1995), the Speech Learning Model - SLM (Flege, 1995) or the Native Language Magnet Theory - NLM (Kuhl and Iverson, 1995). Essentially, it appears that the degree to which L2 contrasts are difficult to perceive depends on how relevant sounds are distributed in the L1 and the L2. How learners perceive L2 sounds can, thus, affect the production of these same sounds. However, this observation indicates that learners are more proficient at marking this distinction in the reading task rather than in the repetition task.

Furthermore, when low vowels appeared to be imitated, they would also display a higher degree of imitation in the F1 dimension, corroborating Babel's (2009) results.

\subsection{Vowel duration}

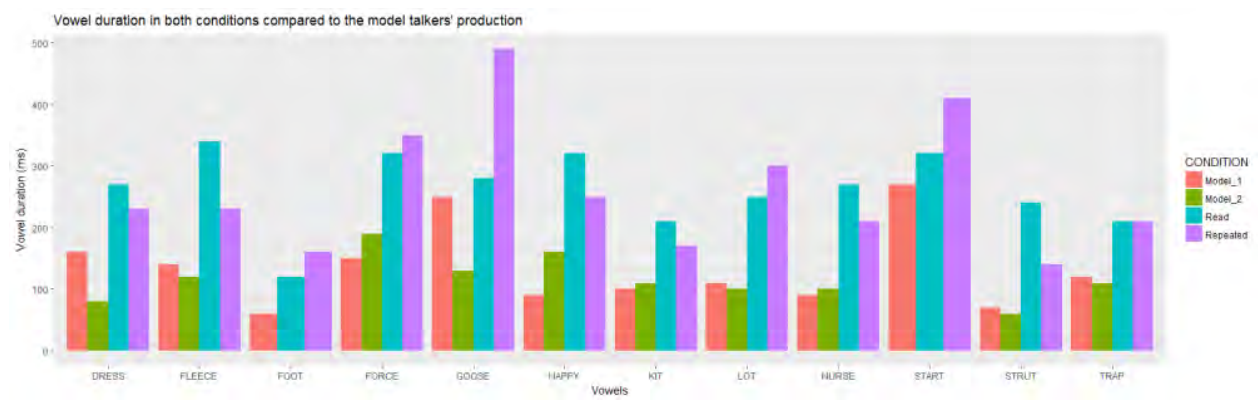

Figure 6. Histogram displaying the overall duration of each vowel in both conditions compared to the model talkers' production. The male model talker's vowel durations are displayed in red, while the female model talker's vowel durations are displayed in green. Participants' vowel durations in the read condition are displayed in blue and those in the repeated condition are displayed in purple.

The non-native speakers produce longer vowels than the native speakers, whatever the task (see Figure 6). Native speakers always speak at a faster rate than non-native speakers and, since speaking at a slower rate results in the production of longer vowels, longer vowels for learners were predictable. We can observe that, overall, the male native speaker $[\mathrm{M}=77.403]$ produces longer vowels than the female native speaker $[\mathrm{M}=74.23]$. A $t$-test determined that the difference between the two model talkers was, however, not significant $[p=0.60]$. Results of another $t$-test showed that the difference regarding the learners' vowel duration between the two tasks was insignificant $[p=0.88]$.

That learners increased the duration for some of the long vowels is interesting, as it might be due to the fact that they have perceived the dichotomy that exists between long and short vowels in English. This argument only applies for 
intermediate learners though, for advanced learners have received phonological training and are undoubtedly aware of this distinction. Yet it appears not necessarily to result in better production.

The following analyses explore the differences in imitation and the patterns that arose across groups. First, we have tested whether vowel duration was influenced by Vowel $\times$ Gender $\times$ Level. The independent variable model talker will be taken into account in a further analysis. Results from ANOVA indicate main effects of Vowel [F $=377.175, p<0.001]$, Gender [ $\mathrm{F}=182.674, p<0.001]$ and Level $[\mathrm{F}=127.931, p<0.001]$. These factors were also significant as twoway Vowel $\times$ Gender $[\mathrm{F}=3.157, p<0.001]$ and Vowel $\times$ Level $[\mathrm{F}=6.606, p<$ $0.001]$ interactions. A three-way Vowel $\times$ Gender $\times$ Level $[\mathrm{F}=1.634, p=0.08]$ interaction was not found. The data was then subset into gender and level and submitted to separate statistical analyses. All results of the statistical analyses are reported in the appendix section.

\subsubsection{Level}

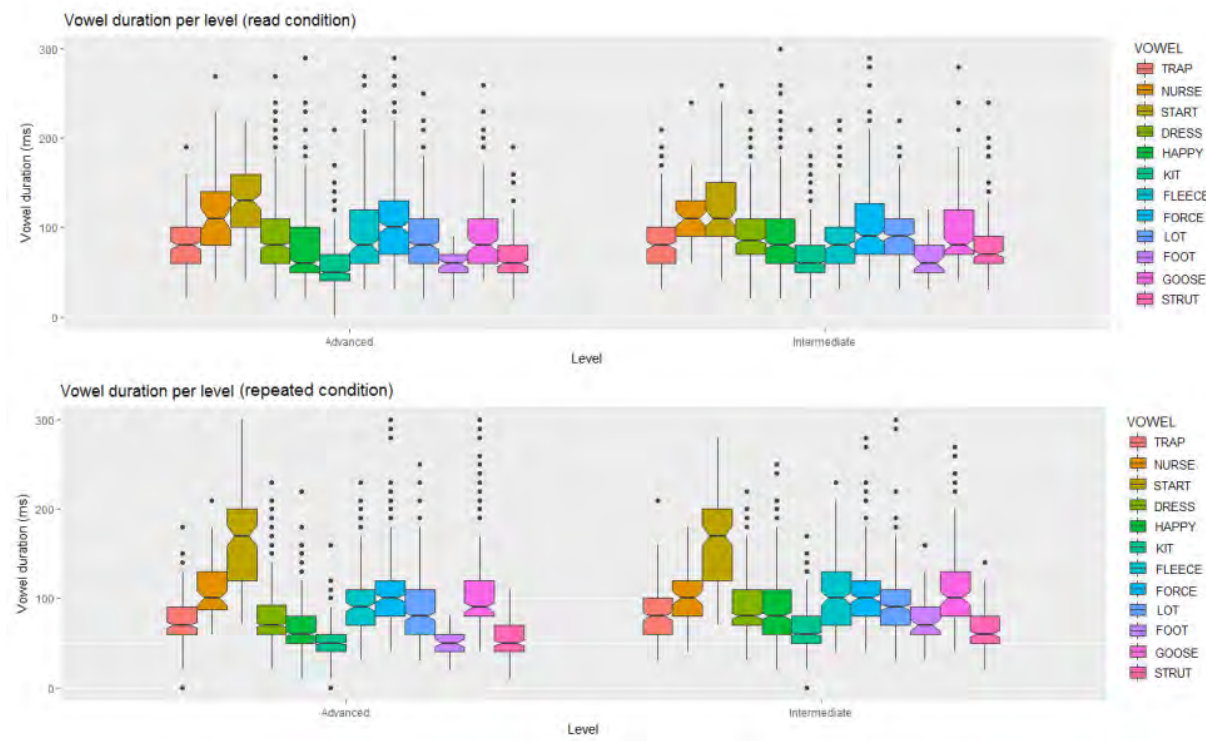

Figure 7. Boxplots displaying vowel duration per level in both tasks

In the reading task, advanced learners tend to produce shorter short vowels and longer long vowels than intermediate learners (see Figure 7). This indicates that advanced learners are more aware of the distinction that exists between short and long vowels in English and that they are, thus, more proficient in the production of durational characteristics. However, statistical analyses (see Table 2) demonstrated that long vowels were not significantly longer when produced by the advanced learners. Most of the short vowels appeared, however, to be 
significantly shorter. This was not the case for the GOOSE vowel. The DRESS and LOT vowels appeared to have similar duration across groups. These observations indicate that advanced learners produce shorter short vowels than intermediate learners, indicating that their production is more similar to those of the model talkers. No firm conclusion can be drawn regarding the production of long vowels.

In the repetition task, it appears that advanced learners produce shorter vowels than intermediate learners, except for the NURSE and START vowels. Results of the statistical analyses (see Table 3) demonstrate that the majority of the short vowels were significantly shorter in that case, except for the FLEECE, FORCE and GOOSE vowels. The same conclusion drawn from the observation of vowel duration in the reading task is also valid in this case.

If we now compare the advanced learners' production between the two tasks we can observe a tendency to vowel shortening. Almost half of the short vowels were found to be significantly shorter (see Table 4 in the appendix). Conversely, the START and GOOSE vowels were proved to be longer in the repetition task. Conclusions that can be drawn from these observations are that all vowels which appear to be significantly shorter between the two tasks are short vowels. Vowels which are significantly longer, or which are not proved to be shorter in the repetition task, are long vowels.

Regarding the intermediate learners' production, we can observe a higher amount of vowel lengthening in the repetition task. Results of the statistical analyses displayed in Statistical analyses (see Table 5) demonstrate that the START, FLEECE and GOOSE vowels are, indeed, significantly longer in this task. This is not the case for the FOOT and FORCE vowels. The STRUT and NURSE vowels appear to be significantly shorter. The TRAP, DRESS, HAPPY, KIT and LOT vowels do not seem to vary in terms of duration between the two tasks. Statistical analyses indicate, however, that the KIT vowel is significantly shorter $[\mathrm{M}(\mathrm{read})=68.576, \mathrm{M}(\mathrm{rep})=65.117), \mathrm{p}<0.001]$. The other vowels do not display any significant amount of shortening or lengthening. Most of the long vowels are lengthened in the repetition task, which could mean that intermediate learners have perceived the dichotomy between short and long vowels. We can also observe that the durational characteristics of short vowels are more subject to imitation than those of long vowels.

Overall, advanced learners tend to produce shorter short vowels. Speaking at a faster rate results in the production of shorter vowels, and more proficient learners tend to speak faster than less proficient learners. This observation confirms that "greater L2 usage and proficiency are associated [...] with increased production experience" (Best and Tyler, 2007: 20). In addition, they shorten the majority of short vowels whereas intermediate learners have not. Since both model talkers produced shorter vowels than learners, this observation suggests that advanced learners converge towards the native speakers to a higher degree than intermediate learners. 
Vowels displaying lengthening in the repetition task across levels are all long vowels. If convergence had occurred, the duration of long vowels would have been shortened. However, these results indicate that all subjects perceived and noticed the distinction that exists between long and short vowels in English. We would suggest that, regarding the production of long vowels, perceptual accommodation occurred, but not phonetic accommodation.

\subsubsection{Gender}

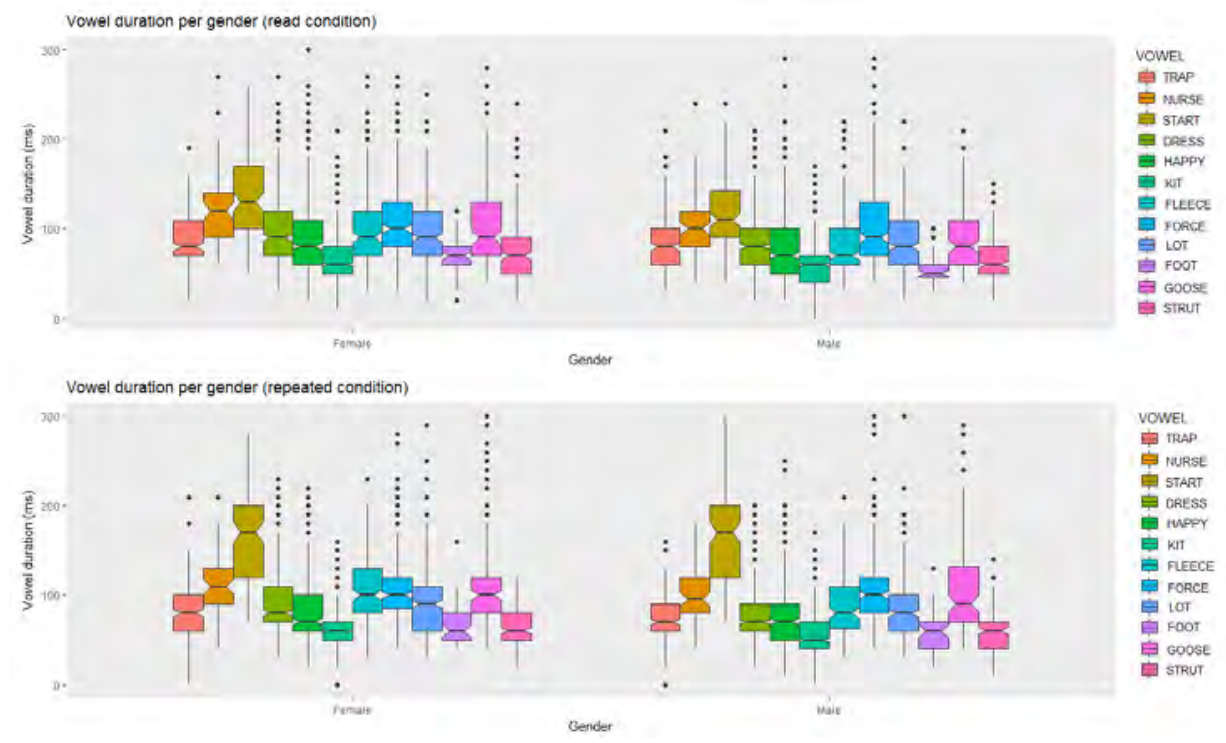

Figure 8. Boxplots displaying vowel duration per gender in both tasks.

Female participants tend to produce longer vowels in the reading task, except for the FORCE vowel (see Figure 8). These observations were proved to be true, since only the FORCE vowel appeared not to be significantly shorter (see Table 6). Moreover, the findings indicate the tendency for female participants to produce longer vowels than male participants.

As in the reading task, it seems that female participants produce longer vowels than male participants in the repetition task. All vowels appear to be longer except the START vowel which seems to have the same duration across groups. Results of a series of $t$-tests (see Table 7) demonstrate that all vowels are significantly longer when produced by the female participants, except for the GOOSE and FORCE vowels. The same conclusion drawn from the analysis of vowel duration in the reading task appears to be valid.

If we now compare the female participants' production between the two tasks, we can observe that the FLEECE, FORCE, GOOSE and START vowels were subject to lengthening and other vowels to shortening. However, statistical 
analyses (see Table 8) demonstrated that only the TRAP, DRESS, HAPPY, KIT and STRUT vowels were significantly shortened. In addition, only the FLEECE vowel was proved to be longer. These observations indicate that female participants shortened the duration of most of the short vowels, and, thus, partly converged towards both model talkers. No definitive conclusion can be drawn from the analysis of long vowels.

Regarding the male participants' production between the two tasks, it appears that, as for female participants, the FLEECE, FORCE, GOOSE and START vowels have been subject to lengthening, in addition to the FOOT vowel. Other vowels seem to display shortening between the two tasks. These observations were statistically proved (see Table 9), except for the NURSE, LOT, FLEECE, FORCE and FOOT vowels. As for female participants, male participants shortened the duration of most of the short vowels. Accommodation towards both model talkers was, only partially manifested. No final conclusion can be drawn from the analysis of long vowels.

Overall, the analysis of vowel duration across gender indicates that female participants produce longer vowels than male participants. All participants shortened the duration of most of the short vowels in the repetition task, indicating that they converged towards both model talkers. No categorical conclusion can be drawn from the analysis of long vowels despite the fact that they seem to have been lengthened but, for most of them, it was not proven statistically. Nonetheless, this indicates that all participants have perceived and noticed the distinction between long and short vowels. We can conclude that short vowels are more subject to imitation than long vowels.

\subsubsection{A cross-analysis between, level, gender and model talker}

Previous observations showed that the male model talker tends to produce longer vowels than the female model talker. Vowels displaying longer duration are the DRESS, FLEECE, GOOSE, LOT, STRUT and TRAP vowels. No comparison is possible for the FOOT and START vowels for they are not produced by the female model talker.

The data was subcategorized to observe whether participants across level and gender would produce longer DRESS, FLEECE, GOOSE, LOT, STRUT and TRAP vowels when repeating the male model talker.

Advanced learners produced longer vowels when repeating the male native speaker, except for the FORCE, HAPPY, KIT, NURSE and STRUT vowels (see Figure 9). However, we have seen that the male model talker tended to produce shorter FORCE, HAPPY and KIT vowels. This is evidence that advanced learners have converged towards both model talkers, except for the NURSE and STRUT vowels. These observations were statistically proved (see Table 10), except for the NURSE, KIT and STRUT vowels. We can conclude that, overall, advanced learners have imitated both model talkers in terms of vowel duration. 

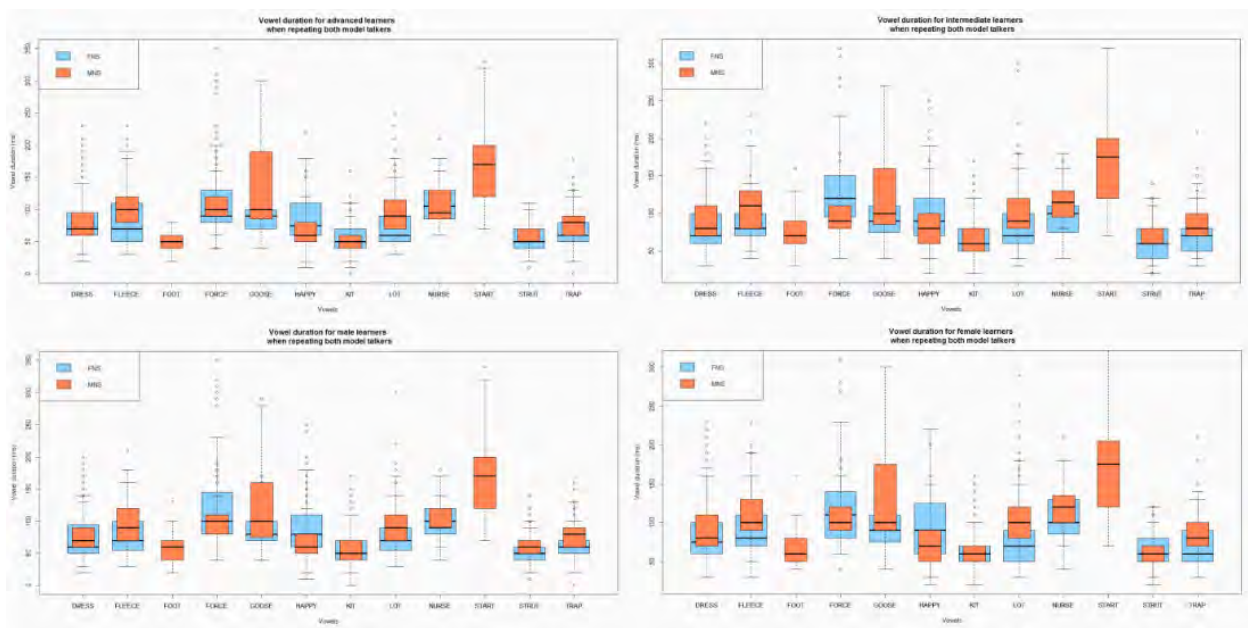

Figure 9. Boxplots displaying vowel duration when repeating both model talkers. The advanced learners' production is displayed on the top left panel; the intermediate learners' production is displayed on the top right panel; the male learners' production is displayed on the bottom left panel, and the female learners' production is displayed on the bottom right panel. FNS corresponds to the female native speaker while MNS corresponds to the male native speaker. Boxes in orange indicate vowel duration in the task of repeating the male native speaker and those in blue indicate vowel duration in the task of repeating the female native speaker. The FOOT and START vowels are not displayed in blue for they were not produced by the female native speaker.

Regarding the intermediate learners' production, it appears that they produced longer vowels when repeating the male model talker, except for the FORCE and HAPPY vowels. The KIT vowel displays no change in duration between the two tasks. Statistical analyses (see Table 11) verified these observations: only the STRUT vowel was not found to be significantly longer. Hence, intermediate learners have imitated both model talkers.

Female learners appear to produce longer vowels in the task of repeating the male native speaker, except for the FORCE, HAPPY and STRUT vowels. The KIT vowel displays no change in duration between the two tasks. These observations were statistically proved (see Table 12) except for the NURSE and STRUT vowels. We can conclude that female learners have, overall, imitated both model talkers.

Male learners seem to produce longer vowels in the task of repeating the male model talker, except for the FORCE and HAPPY vowels. The KIT vowel seems not to display any change in duration between the two tasks. A series of $t$-tests (see Table 13) concurred with these observations, except for the NURSE and STRUT vowels. Male participants have thus, overall, imitated both model talkers.

Among the conclusions that can be drawn from the analysis of vowel duration, we find that all groups have, overall, imitated both model talkers. Furthermore, when the male model talker produces longer vowels participants would, in turn, produce longer vowels. An interesting observation is that the KIT vowel usually 
displays no change in duration between the two tasks. This might be due to the fact that this L2 sound has been perceived according to its articulatory similarities with French /i/, or that, since participants could read the text corresponding to the soundfile that was played, there might have been some grapho-phonemic influence. Learners then produced the KIT vowel in the same way as the HAPPY vowel in terms of duration. We can conclude that there has been a transfer effect from the $\mathrm{L} 1$ to the $\mathrm{L} 2$ regarding the production of this vowel.

To determine whether participants converged more towards the male or the female model talker, mean duration for all vowels was calculated for all participants in the two repetition tasks, and was then subtracted from the mean duration of the model talkers' production. A lower difference in vowel duration value indicates that the participants' vowel duration is closer to the model talkers' production. Results show that the difference value is lower in the task of repeating the female model talker (see Table 14). Participants' production in terms of vowel duration was, then, closer to the production of the female model talker, meaning that they converged more towards her than towards the male model talker.

Table 14. Difference in duration values between the two repetition tasks. The difference in duration is expressed in millisecond.

\begin{tabular}{|l|l|}
\hline Model talker & Difference value (ms) \\
\hline Male & 6.599 \\
\hline Female & 3.655 \\
\hline
\end{tabular}

The same analysis was replicated for each group separately to determine whether the general tendency to accommodate more towards the female model talker was also valid across groups.

Table 15. Difference in duration values across groups in the two repetition tasks. The difference in duration is expressed in millisecond.

\begin{tabular}{|r|l|l|l|l|}
\hline & \multicolumn{4}{|c|}{ Difference value (ms) } \\
\hline $\begin{array}{r}\text { Model } \\
\text { talker }\end{array}$ & $\begin{array}{l}\text { Advanced } \\
\text { learners }\end{array}$ & $\begin{array}{l}\text { Intermediate } \\
\text { learners }\end{array}$ & $\begin{array}{l}\text { Female } \\
\text { learners }\end{array}$ & Male learners \\
\hline Male & 2.895 & 10.303 & 11.414 & 1.784 \\
\hline Female & 1.057 & 6.252 & 6.843 & 0.467 \\
\hline
\end{tabular}

Results indicate that advanced learners converged more towards the male model talker but all other groups seem to have converged more towards the female model talker because the difference in duration values appear to be lower (see Table 15). This confirms that, overall, participants converged more towards the female model talker. This table also suggests that advanced learners converged more than intermediate learners, and male participants more than female participants. 
The same analysis was run through for each vowel separately to determine which vowels, or vowel category, appear to be the most subject to deliberate accommodation. Ideally, a value of 0 would indicate that the participants' mean vowel duration is equal to the model talkers' vowel duration. Negative values indicate that participants' mean vowel duration is shorter than the model talkers' production. When the difference in vowel duration is highly distant from 0 , it means that the participants' production is highly distant to the model talkers' production. Comparison for the FOOT and START vowels is not possible since these vowels were not produced by the female model talker.

Table 16. Difference in duration values for all vowels across groups in the two repetition tasks. The difference in duration is expressed in millisecond.

\begin{tabular}{|c|c|c|c|c|}
\hline \multirow[b]{2}{*}{$\begin{array}{c}\text { Model } \\
\text { talker }\end{array}$} & \multirow[b]{2}{*}{ Vowels } & \multicolumn{3}{|c|}{ Difference value (ms) } \\
\hline & & $\begin{array}{l}\text { Advanced } \\
\text { learners }\end{array}$ & $\begin{array}{l}\text { Intermediate } \\
\text { learners }\end{array}$ & $\begin{array}{l}\text { Female } \\
\text { learners }\end{array}$ \\
\hline \multirow{12}{*}{ Male } & DRESS & 2.9 & 14.642 & 15.525 \\
\hline & FLEECE & -7.7 & 1.2 & 4.6 \\
\hline & FOOT & 3.25 & 23.25 & 18.25 \\
\hline & FORCE & 0.3 & -8.6 & -1.575 \\
\hline & GOOSE & 15.5 & 3.5 & 17.75 \\
\hline & HAPPY & 2.127 & 20 & 13.909 \\
\hline & KIT & 4.97 & 15.96 & 12.608 \\
\hline & LOT & 15.5 & 22.167 & 23.889 \\
\hline & NURSE & 13.5 & 28.5 & 30 \\
\hline & START & -12.25 & -13.25 & -11.33 \\
\hline & STRUT & 1.9 & 13.8 & 10.6 \\
\hline & TRAP & -5.25 & 2.467 & 2.75 \\
\hline \multirow{10}{*}{ Female } & DRESS & 12 & 15.625 & 18.75 \\
\hline & FLEECE & -6.333 & -4.917 & 1.333 \\
\hline & FORCE & 3 & 15.891 & 10 \\
\hline & GOOSE & -22.75 & -17.5 & -19.25 \\
\hline & HAPPY & -10.2 & 6 & -0.4 \\
\hline & KIT & -4.642 & 4.309 & 1.825 \\
\hline & LOT & 6.25 & 12.283 & 10.667 \\
\hline & NURSE & 31 & 14.5 & 27.25 \\
\hline & STRUT & 6.125 & 13.5 & 14.625 \\
\hline & TRAP & -3.875 & 2.833 & 3.625 \\
\hline
\end{tabular}

Advanced learners appear to accommodate more towards the male model talker, as seen previously (see Table 16). Difference in duration values are lower for the DRESS, FORCE, GOOSE, HAPPY, NURSE and STRUT vowels when repeating the male model talker, and lower for the FLEECE, KIT, LOT and TRAP vowels when repeating the female model talker. Advanced learners converged more 
towards the male model talker regarding the production of these vowels. In the task of repeating the male model talker, the FORCE vowel displays the lowest difference in duration value, meaning that this vowel is the one which is the most subject to accommodation. This is also the case in the task of repeating the female model talker.

Intermediate learners converged equally towards both model talkers, as 5 out of 10 vowels display a lower difference in duration value in both cases. The DRESS, FLEECE, FORCE, GOOSE and TRAP vowels show a lower difference in duration values when repeating the male model talker, meaning that participants converged more towards him in terms of vowel duration for these vowels. Intermediate learners converged more towards the female model talker regarding the HAPPY, KIT, LOT, NURSE and STRUT vowels. In addition, the vowel displaying the highest degree of convergence in the task of repeating the male model talker is the FLEECE one, while in contrast it is the TRAP vowel that displays the greatest degree of convergence in the task of repeating the female model talker.

Female participants appear to have converged more towards the female model talker since 6 (FLEECE, HAPPY, KIT, LOT, NURSE and TRAP) out of 10 vowels display a lower difference in duration values. Conversely, the DRESS, FORCE, GOOSE and STRUT vowels were more subject to accommodation in the task of repeating the male model talker. The FORCE vowel displays the highest degree of convergence in the task of repeating the male model talker, while it is the HAPPY vowel in the case of repeating the female model talker.

Male participants have converged equally towards both model talkers. Vowels displaying a lower difference in duration value when repeating the male model talker are the DRESS, FLEECE, FORCE, GOOSE and NURSE vowels, while those displaying a lower difference in duration value when repeating the female model talker are the HAPPY, KIT, LOT, STRUT and TRAP vowels. Vowels from the GOOSE set display the highest degree of accommodation in the task of repeating the male model talker, while it is those from the HAPPY set in the task of repeating the female model talker.

Previous observations showed that all groups except advanced learners tend to converge more towards the female model talker in terms of vowel duration. The analysis of the difference in duration values across groups for each vowel has demonstrated that advanced learners would converge more towards the male model talker. Intermediate and male learners appear to have converged equally towards both model talkers, and female participants to have converged more towards the female model talker. Overall, the DRESS, FORCE and GOOSE vowels display the highest degree of convergence across groups when repeating the male model talker, and the KIT and LOT vowels the highest degree of convergence across groups when repeating the female model talker. We can conclude that, regarding vowel duration, high vowels appear to be more imitated than low vowels. Another observation that can be made from this analysis is that, overall, vowels displaying negative difference in duration values across groups 
are long vowels. This suggests that the mean duration of these vowels when produced by the participants is shorter than when produced by the model talkers. Since there is no dichotomy between short and long vowels in the French phonological system, it appears that participants have difficulty marking the difference existing between short and long vowels in English.

\subsection{Creaky voice}

While segmental phonetic features seem to display deliberate accommodation, one sociolinguistic feature consistently appears for some French advanced female speakers. Creaky voice - a noted feature in the pronunciation of American speakers (Yuasa, 2008) - is a particular phonation type referring to "a vocal effect produced by a very slow [and irregular] vibration of the vocal cords" (Crystal, 1997: 98), which generates very low pitch (F0), as well as low airflow rates (Podesva, 2013: 429). The idea is to compare the number of creak occurrences between the two tasks to determine whether they are related to linguistic idiosyncrasies or to accommodation towards the native speakers.

Creaky voice is characterised by an irregular and low F0, a discontinuous F0 track and by doubled pulses in wide-band spectrogram. All creaky vowels were then tracked.

Results showed that 3 female advanced learners creaked much more than the others, and more in the reading task, while the native speakers did not, or almost not, creak: one occurrence of creak was observed in the female native speaker's production and four in the male native speaker's production. This was not surprising for creaky voice is a noted feature in the American speakers' pronunciation (Yuasa, 2008), but not so much in the British speakers' pronunciation.

According to the Intrinsic Fundamental Frequency (IF0) theory, low vowels have a lower pitch than high vowels (Whalen and Levitt, 1995). The tongue position required in high vowels pulls on the larynx, which increases the tension on the vocal folds, resulting in a higher F0. Since creaky voice is produced with low longitudinal tension of the vocal folds, it is harder to achieve on high vowels. All vowels on which creak occurred in our study were analysed to observe whether low vowels were more subject to creak. Low vowels appearing at the end of prosodic constituents appeared to be privileged (see Table 17), but one female speaker tended to creak more frequently at the beginning of prosodic constituents.

Table 17. Percentage of creaky voice according to vowel height in both tasks. Remaining percentage corresponds either to creak occurring during the production of a diphthong or a schwa.

\begin{tabular}{|l|l|l|}
\hline Task Height & Low & High \\
\hline Reading & $53 \%$ & $21 \%$ \\
\hline Repetition & $51 \%$ & $16 \%$ \\
\hline
\end{tabular}


To conclude, the fact that more occurrences of creak were observable in the reading task indicates both linguistic idiosyncrasies as well as accommodation towards the native speakers. Since the native speakers did not creak and female advanced learners creaked more in the reading than in the repetition task, this means that they may have converged towards the native speakers by creaking less.

\section{Discussion and conclusion}

While most of the studies regarding the process of phonetic accommodation have been conducted amongst speakers sharing the same language or same dialect, the aim of this research study was to determine whether conclusions drawn mostly from intralanguage studies of spontaneous conversations can also be validated in the case of native/non-native interactions.

We expected female speakers to converge more, whatever their level of proficiency, and level to impact the degree of imitation. Contradictory results were observed: male subjects were more proficient at imitating the native speakers than female subjects. In cases where level was found to impact the degree of accommodation, our hypothesis that advanced learners would converge more than intermediate learners was validated. Usually, perceptual and production skills are strongly correlated with accuracy in producing L2 vowels and with the ratio of L2/L1 usage (Best and Tyler, 2007: 20). We have nevertheless seen that all participants had been grouped into levels based on the number of years spent studying English. Some of the intermediate learners would, however, use English on a regular basis. Hence, the proficiency was not even amongst groups, resulting in a high degree of inter-individual variability.

Our results also corroborate the hypothesis that speakers, whether male or female, converge more towards male than towards female speakers (Bilous and Krauss, 1988, Gallois and Callan, 1988, Willemyns et al., 1997). However, this could also be due to the fact that the female model talker produced only five sentences compared to fifteen produced by the male model talker. Fewer vowels were, thus, produced by the female native speaker. Listeners have also been more "in contact" with the voice of the male model talker, which might have led them to more accurately perceive specific characteristics of his voice, resulting in a higher degree of imitation.

Our analysis of vowel duration has demonstrated that non-native speakers produce longer vowels than native speakers, which is correlated to the fact that native speakers speak at a faster rate and, thus, produce shorter vowels. We have observed a general tendency amongst participants to decrease vowel length after auditory exposure to the model talkers, indicating convergence. These observations corroborate previous findings (Zając, 2013; Rojczyk, 2013). Short vowels appeared to be more subject to imitation than long vowels. Since there is no dichotomy between short and long vowels in the French phonological system, 
it appears that participants have difficulty marking this difference in English. The durational characteristics of short vowels appear to be, then, easier to imitate.

We expected low vowels to be more imitated than high vowels, especially in the F1 dimension. Depending on the type of interaction, either high or low vowels were more imitated. This hypothesis was, thus, partially validated. However, the analysis of normalized formant values has demonstrated that low vowels displayed more imitation in the F1 dimension, corroborating Babel's (2009) results. A possible explanation as to why low vowels tend to be more subject to imitation than high vowels is that low vowels "are characterized by greater mouth opening and jaw lowering, which leaves more space for individual variability in their production [...]. Such variability will contribute to more pronounced convergence effects observed in imitation" (Rojczyk, 2013: 67-68). Another interesting observation is that the position of the FLEECE, KIT and HAPPY vowels were more similar to each other in the repetition task than in the reading task. The FLEECE and HAPPY vowels appeared to be pronounced similarly as the KIT vowel. As stated by Best and Tyler (2007: 18), "a learner's L1 and L2 phonological systems are not completely separate but are instead situated within and encompassing interlanguage". Some L2 sounds can be similar, but not identical, to one L1 sound. A similar L2 phone is realised "in an acoustically different manner than an easily identifiable counterpart in the L1" (Flege, 1987: 59), so discrimination is really poor, and no new phonetic category is formed. Nevertheless, the fact that the KIT vowel was subject to imitation in most of the cases indicates that adults are capable of learning to produce new phones. Flege et al (1997) has, indeed, found that experience in English may lead to improvement in the non-native productions of $/ \mathrm{I} /$. Furthermore, the GOOSE vowel, and more particularly the NURSE vowel, displayed the highest degree of imitation. These vowels are not present in the French phonological system and, according to the Perceptual Assimilation Model, discrimination is in this case rather good. Asymmetry between two different phonological systems has reflected better discrimination for the exemplars that fail to show a distinct relationship with perceived similarity to the native category (Flege et al., 1995). Regarding the production of vowels, it has been hypothesized that adult learners will produce new L2 vowels more accurately than similar L2 vowels because they are more likely to create additional phonetic categories for new (and not similar) vowels (Flege, 1988).

Our last analysis dealt with the study of a specific feature - creaky voice which is traditionally ignored or rejected outside the perimeter of phonetic features, and is often referred to as a 'paralinguistic' feature. Our observations indicate that some advanced female learners creaked more than the native speakers, and in the reading task, indicating both linguistic idiosyncrasy and accommodation towards the native speakers. Low vowels also seem to be favoured. In addition, creaky voice has been found to be used prosodically to mark the beginning and/or end of a phrase (Gordon and Ladefoged, 2001). Both scenarios were observed in this analysis. 
The amount of convergence has been found to be affected by the linguistic distance between participants. Talkers sharing the same language or same dialect tend to converge more than talkers from different linguistic communities (Gambi and Pickering, 2013; Kim et al., 2011). Hypotheses tested in this analysis were mostly based on conclusions drawn from spontaneous interactions between people sharing the same language or same dialect. Even if not all of them were validated in the case of deliberate accommodation of L2 speech, the conclusions drawn provide evidence that native and non-native speakers use similar strategies to collapse social distance. In addition, this research study has proved that the different tasks have no effect on imitation in some cases. This can be explained by the high variability phonetic training (Barriuso and Hayes-Harb, 2018). It would have been interesting to design other tasks such as the repetition of an isolated word and/or vowel, and compare the results obtained with those of this analysis.

\section{References}

Abercrombie, David. 1967. Elements of general phonetics. Chicago: Aldine.

Babel, Molly. 2009. Selective vowel imitation in spontaneous phonetic accommodation. UC Berkeley Phonology Lab Report. 163-194.

Babel, Molly. 2011. Imitation in speech. Acoustics Today 7(4). 16-22.

Babel, Molly. 2012. Evidence for phonetic and social selectivity in spontaneous phonetic imitation. Journal of Phonetics 40(1). 177-189.

Babel, Molly, McGuire, Grant, Walters, Sophia and Alice Nicholls. 2014. Novelty and social preference in phonetic accommodation. Laboratory Phonology 5(1). 123-150.

Barriuso, Taylor Anne and Rachel Hayes-Herb. (2018). High variability phonetic training as a bridge from research to practice. The CATESOL Journal 30(1). 177-194.

Best, Catherine T. 1995. A direct realist view of cross-language speech perception. In Winifred Strange (ed.), Speech perception and linguistic experience: issues in crosslanguage research, 171-204. Timonium, MD: York Press.

Best, Catherine T. and Michael D. Tyler. 2007. Nonnative and second-language speech perception: Commonalities and complementarities. In Murray J. Munro and OckeSchwen Bohn (eds.), Second language speech learning: The role of language experience in speech perception and production, 13-34. Amsterdam: John Benjamin.

Bilous, Frances R. and Robert M. Krauss. 1988. Dominance and accommodation in the conversational behaviours of same- and mixed-gender dyads. Language \& Communication 8. 183-194.

Black, John.W. (1949). Loudness of speaking: The effect of heard stimuli on spoken responses. Journal of Experimental Psychology 39. 311-315.

Boersma, Paul and David Weenink. 2015. Praat: doing phonetics by computer (Version 5.4.08). Available from http://www.praat.org.

Bourhis, Richard Y. 1979. Language in ethnic interaction: A social psychological approach. In Howard Giles and Bernard Saint-Jacques (eds.), Language and Ethnic Relations, 117-141. Oxford: Pergamon.

Byrne, Donn. 1997. An overview (and underview) of research and theory within the attraction paradigm. Journal of Social and Personal Relationships 14(3). 417-431. 
Chartrand, Tanya L. and John A. Bargh. 1999. The Chameleon Effect: The PerceptionBehavior Link and Social Interaction. Journal of Personality and Social Psychology 76(6). 893-910.

Coupland, Nicolas and Howard Giles. 1988. Introduction: The communicative contexts of accommodation. Language and Communication 8(3/4). 175-182.

Eisikovits, Edina. 1987. Sex differences in inter-group and intra-group interaction among adolescents. In Anne Pauwels (ed.), Women and Language in Australia and New Zealand Society, 45-58. Sydney: Australian Professional Publications.

Flege, James Emil. 1987. The production of "new" and "similar" phones in a foreign language: evidence for the effect of equivalence classification. Journal of Phonetics 15. 47-65.

Flege, James Emil. 1988. The production and perception of foreign language speech sounds. In Harris Winitz (ed.), Human communication and Its Disorders, A Review. Norwood, 224-240. NJ: Ablex.

Flege, James Emil. 1995. Second Language Speech Learning: Theory, Findings and Problems. In Winifred Strange (ed.), Speech perception and Linguistic Experience: Issues in Cross-Language Research, 233-277. Timomium, MD: York Press.

Flege, James Emil, Munro, Murray J. and Ian R.A. MacKay. 1995. Factors affecting strength of perceived foreign accent in a second language. Journal of the Acoustical Society of America 97(5). 3125-3134.

Flege, James Emil., Bohn, Ocke-Shwen and Sunyoung Jang. 1997. Effects of experience on non-native speakers' production and perception of English vowels. Journal of Phonetics 25. 437-470.

Gallois, Cynthia and Victor J. Callan. 1988. Communication accommodation and the prototypical speaker: Predicting evaluations of status and solidarity. Language and Communication 8. 271-283.

Gambi, Chiara and Martin J. Pickering. 2013. Prediction and imitation in speech. Frontiers in Psychology 4(340). 1-9.

Garnier, Maëva, Lamalle, Laurent and Marc Sato. 2013. Neural correlates of phonetic convergence and speech imitation. Frontiers in Psychology 4(600). 1-15.

Giles, Howard. 1973. Accent mobility: A model and some data. Anthropological Linguistics 15. 87-105.

Giles, Howard and Patricia Johnson. 1987. Ethnolinguistic identity theory: A social psychological approach to language maintenance. International Journal of the Sociology of Language 68. 69- 99.

Giles, Howard, Coupland, Nikolas and Justine Coupland. 1991. Accommodation Theory: Communication, Context and Consequence. In Justine Coupland, Nikolas Coupland and Howard Giles (eds.), Contexts of Accommodation: Developments in Applied Sociolinguistics, 1-68. Cambridge: Cambridge University Press.

Goldinger, Stephen D. 1997. Perception and production in an episodic lexicon. In Keith Johnson and John W. Mullenix (eds.), Talker variability in speech processing, 33-66. San Diego: Academic Press.

Goldinger, Stephen D. 1998. Echoes of Echoes? An Episodic Theory of Lexical Access. Psychological review 105(2). 251-27.

Goldinger, Stephen D. and Tamiko Azuma. 2004. Episodic memory reflected in printed word naming. Psychonomic Bulletin \& Review 11(4).716-722.

Kim, Midam, Horton, William S. and Ann R. Bradlow. 2011. Phonetic convergence in spontaneous conversations as a function of interlocutor language distance. Laboratory Phonology 2(1). 125-156.

Kuhl, Patricia K. and Paul Iverson. 1995. Mapping the perceptual magnet effect for speech using signal detection theory and multidimensional scaling. The Journal of the Acoustical Society of America 97(1). 553-562. 
Lakin, Jessica L., Jefferis, Valerie E., Cheng, Clara Michelle and Tanya L. Chartrand. 2003. The chameleon effect as social glue: Evidence for the evolutionary significance of nonconscious mimicry. Journal of Nonverbal Behavior 27. 145-161

Laver, John and Peter Trudgill. 1979. Phonetic and linguistic markers in speech. In Klaus Scherer and Howard Giles (eds.), Social markers in speech, 1-10. Cambridge: Cambridge University Press.

Laver, John. 1989. Cognitive science and speech: A framework for research. In Helmut Schnelle and Niels O. Bernsen (eds.), Logic and linguistics: Research directions in cognitive science: European perspective, vol. 2, 37-71. Hillsdale, NJ: Lawrence Erlbaum.

Namy Laura L., Nygaard, Lynne C. and Denise Sauerteig. 2002. Gender differences in vocal accommodation: The role of perception. Journal of Language and Social Psychology 21(4). 422-43.

Natale, Michael. 1975. Convergence of Mean Vocal Intensity in Dyadic Communication as a Function of Social Desirability. Journal of Personality and Social Psychology 32(5). 790-804.

Nilsenová, Marie and Marc Swerts. 2012. Prosodic Adaptation in Language Learning. In Jesús Romero-Trillo (ed.), Pragmatics and Prosody in English Language Teaching, 77-94. Dordrecht: Springer Science+Business Media B.V.

Pardo, Jennifer S. 2006. On phonetic convergence during conversational interaction. The Journal of the Acoustical Society of America 119(4). 2382-2393.

Pardo, Jennifer S., Cajory Jay, Isabel and Robert M. Krauss. 2010. Conversational role influences speech imitation. Attention, Perception, \& Psychophysics 72(8). 22542264.

Pardo, Jennifer S., Cajori Jay, Isabel, Hoshino, Risa, Hasbun, Sara Maria, SowemimoCoker, Chantal and Robert M. Krauss. 2013. Influence of Role-Switching on Phonetic Convergence in Conversation. Discourse Processes 50(4). 276-300.

Rojczyk, Arkadiusz. 2013. Phonetic imitation of L2 vowels in a rapid shadowing task. In John Levis and Kimberly LeVelle (eds.), Proceedings of the 4th Pronunciation in Second Language Learning and Teaching Conference, 66-76. Ames, IA: Iowa State University.

Sato, Marc, Grabski, Krystyna, Garnier, Maëva, Granjon, Lionel, Schwartz, Jean-Luc and Noël Nguyen, N. 2013. Converging towards a common speech code: imitative and perceptuo-motor recalibration processes in speech production. Frontiers in Cognitive Sciences 4(422). 1-14.

Tortel, Anne. 2008. « ANGLISH 》. TIPA, Travaux interdisciplinaires sur la parole et le langage 27. 111-122.

Tortel, Anne. 2013. Prosody in a contrastive learner corpus. In Ana Diaz-Negrillo, Nicolas Ballier and Paul Thompson (eds.), Automatic Treatment and Analysis of Learner Corpus Data, 227-249. Amsterdam : John Benjamins. B.V

Watzlawick, Paul, Beavin Bavelas, Janet and Don D. Jackson. 1967. Pragmatics of Human Communication. New-York: Norton.

Willemyns, Michael, Gallois, Cynthia, Callan, Victor J. and Jeffery Pittam. 1997. Accent accommodation in the job interview: Impact of interviewer accent and gender. Journal of Language and Social Psychology 16. 3-22.

Wells. John C. 1982. Accents of English: The British Isles, vol. 2. Cambridge: Cambridge University Press.

Welkowitz, Joan, Feldstein, Stanley, Finkelstein, Markand Lawrence Aylesworth. 1972. Changes in vocal intensity as a function of interspeaker influence. Perceptual and Motor Skills 35. 715-18.

Zuengler, Jane. 1982. Applying accommodation theory to variable performance data in L2. Studies in Second Language Acquisition 4. 181-192. 
Zając, Magdalena. 2013. Phonetic imitation of vowel duration in L2 speech. Research in Language 11(1). 19-29.

\section{Appendix}

Table 2. Statistical analyses resulting from the graphic interpretation of vowel duration per level in the reading task. Mean duration is displayed in millisecond.

\begin{tabular}{|l|c|c|c|}
\hline Vowel type & $\begin{array}{c}\text { Mean duration } \\
\text { (advanced) }\end{array}$ & $\begin{array}{c}\text { Mean duration } \\
\text { (intermediate) }\end{array}$ & $\boldsymbol{p}$-value (t-test) \\
\hline NURSE & 114.918 & 113.167 & 0.41 \\
\hline START & 131.1667 & 122.393 & 0.06 \\
\hline FLEECE & 95.22 & 90.189 & 0.16 \\
\hline FORCE & 110.452 & 107.487 & 0.71 \\
\hline HAPPY & 79.343 & 93.605 & $<0.001$ \\
\hline TRAP & 80.754 & 86.212 & $<0.05$ \\
\hline KIT & 57.789 & 68.576 & $<0.001$ \\
\hline FOOT & 59.25 & 65.641 & $<0.05$ \\
\hline STRUT & 66.278 & 79.152 & $<0.001$ \\
\hline GOOSE & 94.706 & 96.441 & 0.38 \\
\hline
\end{tabular}

Table 3. Statistical analyses resulting from the graphic interpretation of vowel duration per level in the repetition task. Mean duration is displayed in millisecond.

\begin{tabular}{|l|c|c|c|}
\hline Vowel type & $\begin{array}{c}\text { Mean duration } \\
\text { (advanced) }\end{array}$ & $\begin{array}{c}\text { Mean duration } \\
\text { (intermediate) }\end{array}$ & $\boldsymbol{p}$-value $(\boldsymbol{t}$-test) \\
\hline NURSE & 108.5 & 102.5 & 0.84 \\
\hline START & 171.086 & 170.083 & 0.55 \\
\hline TRAP & 73.266 & 80.657 & $<0.01$ \\
\hline DRESS & 80.25 & 90.646 & $<0.001$ \\
\hline HAPPY & 70.845 & 88.125 & $<0.001$ \\
\hline KIT & 54.947 & 65.117 & $<0.001$ \\
\hline LOT & 86.455 & 92.943 & $<0.05$ \\
\hline FOOT & 53.25 & 73.25 & $<0.001$ \\
\hline STRUT & 56.00 & 65.889 & $<0.001$ \\
\hline FLEECE & 94.25 & 100.252 & 0.07 \\
\hline FORCE & 110.65 & 112.677 & 0.34 \\
\hline GOOSE & 119.417 & 113.167 & 0.76 \\
\hline
\end{tabular}

Table 4. Statistical analyses resulting from the graphic interpretation of advanced learners' production between the two tasks. Mean duration is displayed in millisecond.

\begin{tabular}{|l|c|c|c|}
\hline Vowel type & $\begin{array}{c}\text { Mean duration } \\
\text { (read) }\end{array}$ & $\begin{array}{c}\text { Mean duration } \\
\text { (repetition) }\end{array}$ & $\boldsymbol{p}$-value $(\boldsymbol{t}$-test) \\
\hline START & 131.167 & 171.083 & $<0.001$ \\
\hline GOOSE & 94.706 & 119.417 & $<0.05$ \\
\hline TRAP & 80.754 & 73.266 & $<0.01$ \\
\hline HAPPY & 79.344 & 70.85 & $<0.01$ \\
\hline KIT & 57.789 & 59.947 & $<0.01$ \\
\hline
\end{tabular}




\begin{tabular}{|l|c|c|c|}
\hline Vowel type & $\begin{array}{c}\text { Mean duration } \\
\text { (read) }\end{array}$ & $\begin{array}{c}\text { Mean duration } \\
\text { (repetition) }\end{array}$ & $\boldsymbol{p}$-value $(\boldsymbol{t}$-test) \\
\hline FOOT & 59.25 & 53.25 & $<0.05$ \\
\hline STRUT & 66.278 & 56.00 & $<0.001$ \\
\hline NURSE & 114.918 & 108.50 & 0.19 \\
\hline FLEECE & 95.22 & 94.25 & 0.42 \\
\hline FORCE & 110.452 & 110.65 & 0.51 \\
\hline LOT & 86.455 & 89.867 & 0.14 \\
\hline
\end{tabular}

Table 5. Statistical analyses resulting from the graphic interpretation of intermediate learners' production between the two tasks. Mean duration is displayed in millisecond

\begin{tabular}{|l|c|c|c|}
\hline Vowel type & $\begin{array}{c}\text { Mean duration } \\
\text { (read) }\end{array}$ & $\begin{array}{c}\text { Mean duration } \\
\text { (repetition) }\end{array}$ & $\boldsymbol{p}$-value $(\boldsymbol{t}$-test) \\
\hline START & 122.393 & 170.083 & $<0.001$ \\
\hline FLEECE & 90.19 & 100.251 & $<0.01$ \\
\hline GOOSE & 96.441 & 113.167 & $<0.01$ \\
\hline FORCE & 107.487 & 112.677 & 0.14 \\
\hline FOOT & 65.641 & 73.25 & 0.08 \\
\hline NURSE & 113.167 & 102.50 & $<0.05$ \\
\hline STRUT & 79.152 & 65.889 & $<0.001$ \\
\hline
\end{tabular}

Table 6. Statistical analyses resulting from the graphic interpretation of vowel duration per gender in the reading task. Mean duration is displayed in millisecond.

\begin{tabular}{|l|c|c|c|}
\hline Vowel type & $\begin{array}{c}\text { Mean duration } \\
\text { (female) }\end{array}$ & $\begin{array}{c}\text { Mean duration } \\
\text { (male) }\end{array}$ & $\boldsymbol{p}$-value (t-test) \\
\hline TRAP & 87.035 & 79.899 & $<0.05$ \\
\hline NURSE & 121.333 & 106.885 & $<0.05$ \\
\hline START & 134.957 & 118.917 & $<0.01$ \\
\hline DRESS & 98.716 & 83.354 & $<0.001$ \\
\hline HAPPY & 90.533 & 82.406 & $<0.05$ \\
\hline KIT & 66.043 & 60.212 & $<0.001$ \\
\hline FLEECE & 101.887 & 83.481 & $<0.001$ \\
\hline GOOSE & 102.712 & 88.487 & $<0.01$ \\
\hline STRUT & 77.231 & 68.167 & $<0.01$ \\
\hline LOT & 97.315 & 86.346 & $<0.001$ \\
\hline FOOT & 69.231 & 55.75 & $<0.01$ \\
\hline FORCE & 112.864 & 105.07 & 0.93 \\
\hline
\end{tabular}

Table 7. Statistical analyses resulting from the graphic interpretation of vowel duration per gender in the repetition task. Mean duration is displayed in millisecond.

\begin{tabular}{|l|c|c|c|}
\hline Vowel type & $\begin{array}{c}\text { Mean duration } \\
\text { (female) }\end{array}$ & $\begin{array}{c}\text { Mean duration } \\
\text { (male) }\end{array}$ & $\boldsymbol{p}$-value $(\boldsymbol{t}$-test) \\
\hline TRAP & 81.10 & 72.741 & $<0.01$ \\
\hline NURSE & 111.5 & 99.5 & $<0.05$ \\
\hline DRESS & 91.895 & 79.00 & $<0.001$ \\
\hline HAPPY & 81.937 & 77.075 & $<0.05$ \\
\hline KIT & 62.093 & 57.885 & $<0.001$ \\
\hline FLEECE & 104.625 & 89.811 & $<0.001$ \\
\hline
\end{tabular}




\begin{tabular}{|l|c|c|c|}
\hline Vowel type & $\begin{array}{c}\text { Mean duration } \\
\text { (female) }\end{array}$ & $\begin{array}{c}\text { Mean duration } \\
\text { (male) }\end{array}$ & $\boldsymbol{p}$-value $(\boldsymbol{t}$-test) \\
\hline STRUT & 64.611 & 57.278 & $<0.001$ \\
\hline LOT & 93.278 & 86.12 & $<0.05$ \\
\hline FOOT & 68.25 & 58.25 & $<0.05$ \\
\hline GOOSE & 122.083 & 110.50 & 0.1 \\
\hline FORCE & 112.864 & 105.075 & 0.07 \\
\hline
\end{tabular}

Table 8. Statistical analyses resulting from the graphic interpretation of female learners' production between the two tasks. Mean duration is displayed in millisecond.

\begin{tabular}{|l|c|c|c|}
\hline Vowel type & $\begin{array}{c}\text { Mean duration } \\
\text { (read) }\end{array}$ & $\begin{array}{c}\text { Mean duration } \\
\text { (repetition) }\end{array}$ & $\boldsymbol{p}$-value $(\boldsymbol{t}$-test) \\
\hline TRAP & 87.035 & 81.1 & $<0.05$ \\
\hline DRESS & 98.716 & 91.896 & $<0.01$ \\
\hline HAPPY & 90.533 & 81.936 & $<0.01$ \\
\hline KIT & 66.043 & 62.093 & $<0.001$ \\
\hline STRUT & 77.232 & 64.611 & $<0.001$ \\
\hline NURSE & 121.33 & 111.50 & 0.07 \\
\hline LOT & 97.315 & 93.278 & 0.1 \\
\hline FOOT & 69.231 & 68.25 & 0.4 \\
\hline FLEECE & 89.811 & 104.625 & $<0.001$ \\
\hline START & 169.167 & 172.00 & 0.36 \\
\hline FORCE & 105.075 & 112.864 & 0.07 \\
\hline GOOSE & 110.50 & 122.083 & 0.09 \\
\hline
\end{tabular}

Table 9. Statistical analyses resulting from the graphic interpretation of male learners' production between the two tasks. Mean duration is displayed in millisecond.

\begin{tabular}{|l|c|c|c|}
\hline Vowel type & $\begin{array}{c}\text { Mean duration } \\
\text { (read) }\end{array}$ & $\begin{array}{c}\text { Mean duration } \\
\text { (repetition) }\end{array}$ & $\boldsymbol{p}$-value $(\boldsymbol{t}$-test) \\
\hline TRAP & 78.899 & 72.741 & $<0.01$ \\
\hline DRESS & 83.354 & 79.00 & $<0.05$ \\
\hline HAPPY & 82.406 & 77.075 & $<0.05$ \\
\hline KIT & 60.212 & 57.885 & $<0.05$ \\
\hline STRUT & 68.167 & 57.278 & $<0.001$ \\
\hline NURSE & 106.885 & 99.50 & 0.12 \\
\hline LOT & 86.345 & 86.12 & 0.47 \\
\hline START & 118.917 & 169.167 & $<0.001$ \\
\hline GOOSE & 88.487 & 110.50 & $<0.001$ \\
\hline FLEECE & 83.481 & 89.811 & 0.06 \\
\hline FORCE & 105.075 & 110.00 & 0.17 \\
\hline FOOT & 55.75 & 58.25 & 0.27 \\
\hline
\end{tabular}


Table 10. Statistical analyses resulting from the graphic interpretation of advanced learners' production between the two tasks of repetition. FNS corresponds to the task of repeating the female native speaker and MNS to the task of repeating the male native speaker. Mean duration is displayed in millisecond.

\begin{tabular}{|l|c|c|c|}
\hline Vowel type & $\begin{array}{c}\text { Mean duration } \\
\text { (FNS) }\end{array}$ & $\begin{array}{c}\text { Mean duration } \\
\text { (MNS) }\end{array}$ & $\boldsymbol{p}$-value $(\boldsymbol{t}$-test) \\
\hline TRAP & 63.625 & 79.748 & $<0.001$ \\
\hline DRESS & 74.5 & 81.4 & $<0.05$ \\
\hline LOT & 74.454 & 94.389 & $<0.001$ \\
\hline GOOSE & 87.25 & 135.50 & $<0.001$ \\
\hline FLEECE & 84.167 & 100.30 & $<0.01$ \\
\hline FORCE & 117.0 & 104.3 & $<0.05$ \\
\hline HAPPY & 85.80 & 63.991 & $<0.001$ \\
\hline NURSE & 111.0 & 103.5 & 0.2 \\
\hline KIT & 55.961 & 54.334 & 0.1 \\
\hline STRUT & 56.125 & 55.90 & 0.47 \\
\hline
\end{tabular}

Table 11. Statistical analyses resulting from the graphic interpretation of intermediate learners' production between the two tasks of repetition. FNS corresponds to the task of repeating the female native speaker and MNS to the task of repeating the male native speaker. Mean duration is displayed in millisecond.

\begin{tabular}{|l|c|c|c|}
\hline Vowel type & $\begin{array}{c}\text { Mean duration } \\
\text { (FNS) }\end{array}$ & $\begin{array}{c}\text { Mean duration } \\
\text { (MNS) }\end{array}$ & $\boldsymbol{p}$-value $(\boldsymbol{t}$-test) \\
\hline TRAP & 70.38 & 87.479 & $<0.001$ \\
\hline DRESS & 78.125 & 93.150 & $<0.001$ \\
\hline LOT & 80.672 & 101.056 & $<0.001$ \\
\hline GOOSE & 92.50 & 123.50 & $<0.001$ \\
\hline FLEECE & 85.085 & 109.20 & $<0.001$ \\
\hline NURSE & 94.50 & 118.50 & $<0.01$ \\
\hline STRUT & 63.50 & 67.80 & 0.1 \\
\hline FORCE & 129.40 & 95.612 & $<0.001$ \\
\hline HAPPY & 102.00 & 81.818 & $<0.001$ \\
\hline
\end{tabular}

Table 12. Statistical analyses resulting from the graphic interpretation of female learners' production between the two tasks of repetition. FNS corresponds to the task of repeating the female native speaker and MNS to the task of repeating the male native speaker. Mean duration is displayed in millisecond.

\begin{tabular}{|l|c|c|c|}
\hline Vowel type & $\begin{array}{c}\text { Mean duration } \\
\text { (FNS) }\end{array}$ & $\begin{array}{c}\text { Mean duration } \\
\text { (MNS) }\end{array}$ & $\boldsymbol{p}$-value (t-test) \\
\hline TRAP & 71.125 & 87.750 & $<0.001$ \\
\hline DRESS & 81.250 & 94.025 & $<0.001$ \\
\hline LOT & 78.908 & 102.778 & $<0.001$ \\
\hline GOOSE & 90.75 & 137.75 & $<0.001$ \\
\hline FLEECE & 91.333 & 112.60 & $<0.001$ \\
\hline NURSE & 107.25 & 120.00 & 0.07 \\
\hline FORCE & 124.00 & 102.525 & $<0.001$ \\
\hline HAPPY & 95.60 & 75.727 & $<0.001$ \\
\hline STRUT & 64.625 & 64.600 & 0.5 \\
\hline
\end{tabular}


Table 13. Statistical analyses resulting from the graphic interpretation of male learners' production between the two tasks of repetition. FNS corresponds to the task of repeating the female native speaker and MNS to the task of repeating the male native speaker. Mean duration is displayed in millisecond.

\begin{tabular}{|l|c|c|c|}
\hline Vowel type & $\begin{array}{c}\text { Mean duration } \\
\text { (FNS) }\end{array}$ & $\begin{array}{c}\text { Mean duration } \\
\text { (MNS) }\end{array}$ & $\boldsymbol{p}$-value (t-test) \\
\hline TRAP & 62.784 & 79.407 & $<0.001$ \\
\hline DRESS & 71.375 & 80.525 & $<0.01$ \\
\hline LOT & 76.218 & 92.667 & $<0.001$ \\
\hline GOOSE & 89.00 & 121.25 & $<0.001$ \\
\hline FLEECE & 77.796 & 96.90 & $<0.001$ \\
\hline NURSE & 98.25 & 102.00 & 0.32 \\
\hline STRUT & 55.00 & 59.10 & 0.08 \\
\hline FORCE & 122.40 & 97.475 & $<0.001$ \\
\hline HAPPY & 92.20 & 70.137 & $<0.001$ \\
\hline
\end{tabular}

